\title{
Technological Innovation in the Airline Industry: The Impact of Regional Jets
}

\author{
by \\ Jan K. Brueckner \\ Department of Economics \\ University of California, Irvine \\ 3151 Social Science Plaza \\ Irvine, CA 92697 \\ e-mail: jkbrueck@uci.edu \\ and \\ Vivek Pai \\ Department of Economics \\ University of California, Irvine \\ 3151 Social Science Plaza \\ Irvine, CA 92697 \\ e-mail:vpai@uci.edu
}

February 2007

\begin{abstract}
This paper explores the impact of the regional jet (RJ), an important new technological innovation in the airline industry, on service patterns and service quality. The evidence shows that RJs were used to provide service on a large number of new hub-and-spoke (HS) and point-topoint (PP) routes. In addition, they replaced discontinued jet and turboprop service on many HS routes, as well as supplementing continuing jet service on such routes. When replacement or supplementation by RJs occurred, passengers benefited from better service quality via higher flight frequencies. The paper's theoretical analysis predicts that the frequency advantage of RJs over jets, a consequence of their small size, should have led to the emergence of PP service in thin markets where such service was previously uneconomical. However, the evidence contradicts this prediction, showing that markets attracting new PP service by RJs had demographic characteristics similar to those of markets that already had jet PP service or attracted it after 1996.
\end{abstract}




\title{
Technological Innovation in the Airline Industry: The Impact of Regional Jets
}

by

\author{
Jan K. Brueckner and Vivek Pai
}

\section{Introduction}

While the airline industry has experienced a number of significant institutional innovations over the years, including the adoption of hub-and-spoke networks and frequent flier programs and the use of yield management techniques, true technological innovations have been less frequent. The most significant such innovation over the last fifty years was the emergence of the jet passenger aircraft in the 1960s. More recently, the 1990s have witnessed another technological innovation that, while less dramatic than the jet revolution, is nevertheless significant. This innovation is the introduction of the regional jet aircraft, which was made possible by the development of efficient jet engines suitable for smaller planes. ${ }^{1}$

Regional jets (RJs) offer a previously unavailable combination of attributes. They combine a relatively small passenger capacity, usually 70 seats or less, with a relatively long range (1500 miles), a high cruising speed comparable to that of mainline jets (over $500 \mathrm{mph}$ ), and a level of passenger comfort that almost equals that of mainline jets. Turboprop aircraft, while providing a similar small capacity, have a shorter range (less than 1000 miles), lower cruising speed (350 mph), and provide less comfort, mainly because of higher noise levels. A disadvantage of both aircraft types relative to mainline jets is a higher operating cost per seat mile. ${ }^{2}$

Because RJs are superior to turboprops on most dimensions, passengers prefer them, and this preference is one explanation for the explosion of RJ service since the late 1990s. This explosion can be seen in Table 1, which shows the number of domestic routes with RJ service (possibly in combination with other types of service) for each year between 1990 and 2005. This route count pertains only to four major airlines (American, Continental, Delta and Northwest) for which RJ usage data are available over this period, as explained further below. As shown in the table, RJ service gained a foothold over the early 1990s and grew dramatically after 
1996. By 2005, RJ service by the four major airlines was observed on over 1000 routes. $^{3}$

While RJs have been widely used to replace turboprops as hub feeders from smaller endpoints, their attributes admit other uses as well. Since RJs offer jet-like features but with smaller capacities, they can be used to boost flight frequencies on routes that would normally be served by jets, either by supplementing or replacing jet service. The small size of RJs allows flight frequencies to be raised without the penalty of empty seats, which would be incurred if additional mainline jets were used to boost frequency on a route.

This frequency advantage of RJs may also lead to the provision of service that was previously uneconomical. To understand this prediction, focus on a city-pair market involving small or medium-size endpoints that are relatively far apart, and consider whether point-to-point service (involving a direct flight) is viable in the market. On the one hand, use of turboprops is ruled out by the long flight distance. In addition, market's small size means that adequate flight frequency cannot be sustained with mainline jet service. Filling a mainline jet would only be possible if flight frequency were so low as to make the service non-viable (e.g., once a day or less). With point-to-point service thus uneconomical, the only option is to serve the market with connecting flights through a hub airport.

RJs change this picture by offering sufficient range to serve the market and a small enough capacity to allow a viable level of flight frequency. Thus, the introduction of RJs could allow point-to-point service in a relatively thin city-pair market like the one in question. Note that, when it occurs, such service bypasses hubs and thus tends to undermine existing hub-and-spoke networks.

The purpose of this paper is to document and analyze the patterns of service for RJs after 1996, when their usage surged. Using the Department of Transportation's T-100 database, the paper explores the growth in RJ service on both hub-and-spoke and point-to-point routes. The analysis focuses separately on routes that had no airline service at the start of the period, gaining service after 1996, and on routes where RJs replaced or supplemented existing service. The paper also attempts to evaluate the "new-routes" hypothesis described above, which predicts new point-to-point RJ service on routes that could not be served economically by jets. 
The existing economics literature on RJs and regional airlines is extremely sparse. Dresner et al. (2002) analyze Continental's regional jet usage to determine whether RJs supplement jets or replace turboprops, and they also attempt to assess whether the availability of RJs affects the demand for air travel. The authors find that RJs are mainly used on new huband-spoke routes and that they appear to increase demand on routes where turboprops are replaced. General Accounting Office (2001) provides related additional information on RJ usage. Forbes and Lederman (2005) do not focus on RJs directly but instead study patterns of vertical integration between regional feeders and the major airlines. The authors show that the major airlines are likely to rely on trusted regional subsidiaries, rather than on independent regional carriers, on those routes where schedule disruptions are costly to the major carrier and likely to occur (on hub routes and routes prone to bad weather).

The plan of this paper is as follows. The main empirical findings are presented in section 4, following a discussion of the data in section 3. To motivate the new-routes hypothesis, section 2 presents a simple theoretical model that shows how the introduction of an aircraft with small seat capacity can generate point-to-point service in a market where it was previously unavailable. For readers who have grasped the new-routes hypothesis but are uninterested in its theoretical illustration, section 2 can be skipped without loss of continuity. Section 5 offers conclusions.

\section{Model}

\section{2a. The setup}

The purpose of the model is to illustrate the new-routes hypothesis by showing how the emergence of small jets can lead to new point-to-point (PP) service in a city-pair market that previously enjoyed only connecting service via a hub. In the model, only one group of passengers, those with a high valuation of flight frequency, switches to PP service. The remaining low-valuation passengers continue to make connecting trips.

In the model, an airline can charge higher fares as its flight frequency rises, following the analysis of Brueckner (2004). The reason is that higher frequency reduces "schedule delay" for the passenger, allowing travel to occur closer to the preferred departure time. Assuming 
that the airline is a perfectly discriminating monopolist, able to extract all surplus from the consumer, its fare $p$ is then given by the relationship $p=y-\gamma / f$, where $y$ is a constant, $f$ the number of flights, and $\gamma$ is a parameter related to the disutility of schedule delay. Note that an increase in $f$, by reducing schedule delay, allows the airline to raise $p .4$

To address the question at hand, this setup is expanded to admit two types of consumers, A and B, who are differentiated by their schedule delay costs, denoted $\gamma_{A}$ and $\gamma_{B}$ (they also have different $y$ 's, $y_{A}$ and $\left.y_{B}\right)$. The A-types represent business travelers, who have a strong aversion to schedule delay, implying $\gamma_{A}>\gamma_{B}$. Their population share is $\delta$, with $1-\delta$ giving the B-types' share.

The analysis also distinguishes between two types of routings, as seen in Figure 1. The citypair market of interest is XZ, which can be served in point-to-point fashion or via connecting service through hub H. Connecting service, however, involves extra travel time, which imposes utility costs of $\alpha_{A}$ and $\alpha_{B}$ on the two types of passengers.

Given these elaborations, the perfectly-discriminating monopolist will charge four different fares to XZ passengers, depending on their type and routing. Letting $d$ and $c$ superscripts denote direct (point-to-point) and connecting service, these fares are given by

$$
\begin{aligned}
& p_{A}^{d}=y_{A}-\frac{\gamma_{A}}{f^{d}} \\
& p_{A}^{c}=y_{A}-\alpha_{A}-\frac{\gamma_{A}}{f^{c}} \\
& p_{B}^{d}=y_{B}-\frac{\gamma_{B}}{f^{d}} \\
& p_{B}^{c}=y_{B}-\alpha_{B}-\frac{\gamma_{B}}{f^{c}},
\end{aligned}
$$

where $f^{d}$ and $f^{c}$ are the flight frequencies for the two routings. Note that because $\gamma_{A}>\gamma_{B}$, type-A fares respond more than type-B fares to an increase in flight frequency. Observe also that, since fares extract all surplus, each passenger type is indifferent between direct and connecting travel. The monopolist can then divide the passengers between direct and connecting service so as to maximize profit, as seen below. The total number of XZ passenger of both types is normalized to unity, with the total comprised of $\delta$ A-types and $1-\delta$ B-types. 
For completeness, the analysis also considers "local" passengers in city-pair markets XH and $\mathrm{ZH}$, who make only direct trips. The two local markets are assumed to be large in size relative to $\mathrm{XZ}$, with $N>1$ passengers traveling in each market. Both $\mathrm{A}$ and B-types are represented among these passengers, and the fares paid are equal to (2) and (4) with $\alpha_{A}$ and $\alpha_{B}$ deleted. The reason is that local passengers experience the same flight frequency $\left(f^{c}\right)$ as connecting passengers, but do not incur their longer trip time. The average fare paid by local passengers is therefore

$$
\widetilde{p}=\widetilde{y}-\frac{\widetilde{\gamma}}{f^{c}}
$$

where $\widetilde{y}=\delta y_{A}+(1-\delta) y_{B}$ and $\widetilde{\gamma}=\delta \gamma_{A}+(1-\delta) \gamma_{B}$ are the average $y$ and $\gamma$ values.

To derive the flight frequencies $f^{d}$ and $f^{c}$, aircraft are assumed for simplicity to operate with no empty seats (with a 100\% load factor). Letting $s$ denote aircraft seating capacity and $q$ denote total passengers on a route, $f$ then satisfies the relationship $f s=q$, which says that number of flights times seats per flight equals total passengers (so that $f=q / s$ ).

A key feature of the analysis is that $s$ may differ on the three routes shown in Figure 1, contributing to a difference in flight frequencies. For the hub routes $\mathrm{XH}$ and $\mathrm{ZH}, s$ assumes the value $s^{c}$, representing a large aircraft that is appropriate for serving these dense routes. Assuming that route XZ is too long to be served by turboprop aircraft, the airline's only option in the pre-RJ era would have been to use aircraft of size $s^{c}$ on the route. However, the emergence of RJs would allow $s$ to be set at a smaller value $s^{d}<s^{c}$, more appropriate for the potentially low traffic level on this route.

The traffic levels $(q)$ on the three routes are also needed to compute flight frequencies, and these levels are affected by the division of XZ passengers between direct and connecting service. This division is ultimately chosen by the airline to maximize profit. Let $\theta_{A}$ denote the share of type-A passengers in the XZ market who travel direct, with $1-\theta_{A}$ giving the share who make a connecting trip. Let $\theta_{B}$ be defined analogously for type-B passengers. Then, recalling that market XZ has $\delta$ type-A and $1-\delta$ type-B passengers, traffic on the direct XZ route equals

$$
q^{d}=\delta \theta_{A}+(1-\delta) \theta_{B}
$$


Correspondingly, traffic on each of the $\mathrm{XH}$ and $\mathrm{ZH}$ routes is given by

$$
q^{c}=N+1-q^{d} .
$$

In this expression, $N$ gives the number of local passengers, and $1-q^{d}$ gives the number of connecting XZ passengers.

Combining the above information, flight frequencies can be derived and total revenue for the monopoly airline can be computed. Substituting $1 / f^{c}=s^{c} / q^{c}$ and $1 / f^{d}=s^{d} / q^{d}$ into the fare formulas in (1)-(5), and multiplying fares by the appropriate traffic levels, revenue is equal to

$$
\begin{aligned}
& 2\left(\widetilde{y}-\frac{\widetilde{\gamma} s^{c}}{q^{c}}\right) N+\left(y_{A}-\frac{\gamma_{A} s^{d}}{q^{d}}\right) \delta \theta_{A}+\left(y_{B}-\frac{\gamma_{B} s^{d}}{q^{d}}\right)(1-\delta) \theta_{B}+ \\
& \quad\left(y_{A}-\alpha_{A}-\frac{\gamma_{A} s^{c}}{q^{c}}\right) \delta\left(1-\theta_{A}\right)+\left(y_{B}-\alpha_{B}-\frac{\gamma_{B} s^{c}}{q^{c}}\right)(1-\delta)\left(1-\theta_{B}\right) .
\end{aligned}
$$

Note that the 2 factor in the first line of (8) arises because there are two local markets.

The airline's costs are computed by multiplying cost per seat times traffic on each of the three routes it operates. Cost per seat is $\tau^{c}$ for aircraft of size $s^{c}$ on the connecting routes and $\tau^{d}$ is the cost per seat for aircraft of size $s^{d}$ on the direct route. Since large aircraft have lower cost per seat over a given distance, $s^{c}>s^{d}$ would imply $\tau^{c}<\tau^{d}$, provided all the route segments are of equal length, as in Figure $1 .^{5}$ Applying these seat costs to traffic on the three routes, airline costs are then equal to

$$
2 \tau^{c} q^{c}+\tau^{d} q^{d} .
$$

\section{2b. Choice of $\theta_{A}$ and $\theta_{B}$}

The airline's goal is to maximize profit $\pi$, equal to (8) minus (9), and its only choice variables are $\theta_{A}$ and $\theta_{B}$, which determine the division of type-A and type-B traffic between 
direct and connecting service. Note that $\theta_{A}$ and $\theta_{B}$ appear directly in (8) but that both $q^{d}$

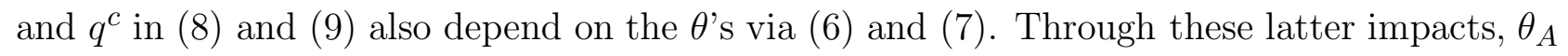
and $\theta_{B}$ affect flight frequencies (via the ratio terms in (8)) and thus the fares that the airline is able to charge. For example, when $\theta_{A}$ increases, $q^{d}$ rises and $q^{c}$ falls, raising (lowering) flight frequencies and fares on the direct (connecting) routes. The effects of these fare changes are amplified by changes in type-A traffic on the two routes.

Making all these influences of $\theta_{A}$ and $\theta_{B}$ explicit, profit can be written as $\pi\left(\theta_{A}, \theta_{B}\right)$. Some tedious analysis (available on request) establishes two useful facts about this profit function. First, $\pi\left(\theta_{A}, \theta_{B}\right)$ is a strictly concave function of $\theta_{B}$, which means that the optimal $\theta_{B}$ could lie anywhere in the interval $[0,1]$, including the endpoints. Second, provided that $\gamma_{A}$ is large relative to $\gamma_{B}$, profit is a strictly convex function of $\theta_{A} \cdot{ }^{6}$ Under this condition, the optimal $\theta_{A}$ is a corner solution, equal to either 0 or 1 , which indicates that either all or none of the A-types travel direct.

Given these properties of $\pi\left(\theta_{A}, \theta_{B}\right)$, conditions for a particularly simple division of XZ traffic between direct and connecting service are easily stated. Under this division, all of the B-types use connecting service, while all of the A-types travel direct. In other words, the equalities $\theta_{B}=0$ and $\theta_{A}=1$ both hold. $^{7}$ For this outcome to be optimal, the following conditions must be satisfied:

$$
\begin{array}{r}
\frac{\partial \pi(1,0)}{\partial \theta_{B}}<0 \\
\pi(1,0)-\pi(0,0)>0 .
\end{array}
$$

These conditions indicate that movement away from $\left(\theta_{A}, \theta_{B}\right)=(1,0)$ toward a higher $\theta_{B}$ (eq. (10)) or lower $\theta_{A}$ (eq. (11)) reduces profit. While these conditions are necessary, they do not rule out the possibility that $\pi(1,0)$ is less than $\pi\left(0, \theta_{B}\right)$ for some $\theta_{B}>0$. The condition

$$
\frac{\partial \pi(0,0)}{\partial \theta_{B}}<0
$$

when combined with (11), is sufficient to exclude this possibility. Together, (10)-(12) ensure the optimality of $\left(\theta_{A}, \theta_{B}\right)=(1,0)$. 
Additional computations (again available on request) show that (10) reduces to the following condition:

$$
\Omega \equiv(1-\delta)\left(\alpha_{B}+2 \tau^{c}-\tau^{d}\right)+\frac{s^{d} \delta(1-\delta)\left(\gamma_{A}-\gamma_{B}\right)}{\delta^{2}}+\frac{s^{c}(1-\delta) N\left(\gamma_{B}-2 \widetilde{\gamma}\right)}{(N+1-\delta)^{2}}<0
$$

To understand the first term in the $\Omega$ expression in (13), note that when $\theta_{B}$ increases (sending more B-types on direct trips), the airline gains from not needing to offer the redirected passengers the connecting fare discount, $\alpha_{B}$. It also saves connecting seat costs of $2 \tau^{c}$ while incurring direct seat costs of $\tau^{d}$. To derive the first ratio term in (13), recall from (8) that the lower fares required as compensation for schedule delay reduce revenue, with the revenue loss for direct passengers equal to $\left(\gamma_{B} s^{d} / q^{d}\right)(1-\delta) \theta_{B}+\left(\gamma_{A} s^{d} / q^{d}\right) \delta \theta_{A}$. The first term in this expression rises with $\theta_{B}$ even though $q^{d}$ increases (a consequence of the larger numerator), which raises the revenue loss. However, with the numerator unchanged, the second term falls. Since $\gamma_{A}>\gamma_{B}$, the latter effect dominates, so that the overall revenue loss falls as $\theta_{B}$ rises. The first ratio term in (13) captures the resulting positive effect on profit (note that $\delta$ in the denominator equals $q^{d}$ ). This profit gain is increasing in $s^{d}$, the aircraft size on the direct route, a fact that plays a key role below. The last term in (13) gives the effect of $\theta_{B}$ on schedule-delay losses for local and connecting passengers $\left(N+1+\delta\right.$ in the denominator equals $\left.q^{c}\right) .{ }^{8}$

Eq. (11), the second of the above conditions, reduces to

$$
\begin{aligned}
\Phi \equiv \delta\left(\alpha_{A}+2 \tau^{c}-\tau^{d}\right) & -2 N\left(\frac{\widetilde{\gamma} s^{c}}{N+1+\delta}-\frac{\widetilde{\gamma} s^{c}}{N+1}\right) \\
& -(1-\delta)\left(\frac{\gamma_{B} s^{c}}{N+1-\delta}-\frac{\gamma_{B} s^{c}}{N+1}\right)-\delta\left(\frac{\gamma_{A} s^{d}}{\delta}-\frac{\gamma_{A} s^{c}}{N+1}\right) \\
=\delta\left(\alpha_{A}+2 \tau^{c}-\tau^{d}\right) & -\gamma_{A} s^{d}+\frac{\delta s^{c}\left[(1-\delta)\left(\gamma_{A}-\gamma_{B}\right)+N\left(\gamma_{A}-2 \widetilde{\gamma}\right)\right]}{(N+1)(N+1-\delta)}>0 .
\end{aligned}
$$

The first term (14) is analogous to corresponding term (13), while the remaining terms in the first two lines of (14) capture the changes in the revenue loss from schedule delay, with the second term pertaining to local passengers and the third term to connecting XZ passengers. 
Note that the shift of the A-types reduces traffic on the connecting routes from $N+1$ to $N+1-\delta$, which alters the inverse frequency ratios that appear in parentheses. The last term gives the change in the schedule-delay loss for the shifted type- $A$ passengers themselves. All these terms collapse into the last expression in the third line of (14), which is positive, minus $\gamma_{A} s^{d} .{ }^{9}$ A key difference relative to (13) is the negative effect of $s^{d}$, indicating that the profit gain from shifting all the A-types to direct service is smaller the larger is the aircraft size on the direct route. This outcome reflects the disadvantage of lower frequency, which raises the revenue loss from schedule delay on that route.

In a similar fashion, the condition (12) reduces to

$$
\Lambda=(1-\delta)\left(\alpha_{B}+2 \tau^{c}-\tau^{d}\right)-\frac{s^{c} \delta(1-\delta)\left(\gamma_{A}-\gamma_{B}\right)}{(N+1)^{2}}+\frac{s^{c}(1-\delta) N\left(\gamma_{B}-2 \widetilde{\gamma}\right)}{(N+1)^{2}}<0
$$

\section{2c. The emergence of point-to-point service}

With this background, the question of whether the emergence of RJs leads to new pointto-point service can be addressed. To start, consider an initial situation where only aircraft of size $s^{c}$ (mainline jets) are available, so that $s^{d}=s^{c}$ and $\tau^{d}=\tau^{c} .^{10}$ In this situation, suppose the model parameters make $\theta_{A}=0$ and $\theta_{B}=0$ optimal, so that no direct XZ service is offered. Using the previous logic, optimality of this outcome is ensured when (10) and (12) hold along with the reverse of the inequality in (11), so that the expressions in (13)-(15) are all negative when $s^{d}=s^{c}$ and $\tau^{d}=\tau^{c}{ }^{11}$

Now suppose that RJs are introduced, allowing the XZ route to be served by aircraft with $s^{d}<s^{c}$ and $\tau^{d}>\tau^{c}$. The first observation is that, if the expressions in (10) and (12) are initially negative, they remain negative after $s^{d}$ and $\tau^{d}$ assume their new values. This conclusion follows because the $\Omega$ and $\Lambda$ expressions in (13) and (15) are decreasing in $\tau^{d}$ and increasing (or constant) in $s^{d}$. Therefore, if connecting travel for the B-types $\left(\theta_{B}=0\right)$ was desirable in the absence of RJs, it remains so following their introduction.

The second and more-important observation is that a lower $s^{d}$ and higher $\tau^{d}$ may lead to an increase in the value of $\Phi$ in (14). Although the net effect is ambiguous in general since $s^{d}$ and $\tau^{d}$ both appear in $\Phi$ with negative coefficients, this outcome may emerge if the decline in 
$s^{d}$ is large relative to the increase in $\tau^{d}$. Given that cost per seat in RJs is not dramatically higher than the cost in mainline jets despite their much smaller size, this condition is realistic. In the limiting case, where seat costs are independent of aircraft size, RJs would allow higher frequency with no increase in cost, and their introduction would unambiguously raise the magnitude of $\Phi$.

The crucial conclusion is that such an increase can reverse the sign of $\Phi$, making it positive as in (14), so that $\theta_{A}=1$ becomes optimal. Thus, the introduction of RJs can lead to the emergence of direct, point-to-point service in market XZ, which is used only by the type-A passengers. The intuitive reason is that, by allowing higher flight frequency on direct trips, the availability of a smaller aircraft can tip the balance in the favor of such trips for the passengers most sensitive to schedule delay. This conclusion yields the "new-routes hypothesis," which asserts that RJs allow the provision of new point-to-point service that was not economical when only larger aircraft were available.

The remainder of the paper provides empirical evidence on the patterns of RJ usage. The goal is both to document the impact of this important technological innovation and to test the new-routes hypothesis.

\section{Data}

Data for the analysis of airline service patterns were drawn from the Department of Transportation's T-100 service-segment database. Derived from Form 41, which large certificated carriers have submitted since 1990, ${ }^{12}$ the T-100 database contains aircraft types and numbers of departures by carrier for each non-stop U.S. route segment, along with other information. Beginning in the third quarter of 2002, reporting gaps were closed by the requirement that all carriers, including regional and commuter air carriers, submit data.

Although RJ service began to grow dramatically starting in 1997, the reporting gaps that existed before 2002 mean that much of this service (which was operated by non-reporting regional carriers) is unobservable. Fortunately, however, regional carriers that operated as subsidiaries of large certificated carriers submitted data sporadically over the first half of 1990s and did so consistently starting in 1997. These carriers are American Eagle, a subsidiary 
of AMR (the parent of American Airlines), and Executive Airlines, a subsidiary of American Eagle; ExpressJet, a former subsidiary of Continental Airlines; Atlantic Southeast and Comair, subsidiaries of Delta Airlines; Pinnacle/Express Airlines, a subsidiary of Northwest Airlines, and Mesaba Airlines, partially owned by Northwest. Business Express, an independent airline that codeshared with Delta and Northwest prior to its absorbtion by American Eagle in 2000, also reported data starting in 1997.

Given the availability of data for the period of interest, the analysis focuses solely on these four major carriers (American, Continental, Delta and Northwest) and their associated regional carriers, whose route segments were assigned to the major carrier. Hubs for the different carriers over the 1996-2005 period, needed to determine hub-and-spoke (HS) and PP routes, are as follows. American's hubs are Dallas-Ft. Worth, Chicago-O'Hare, Miami, and St. Louis; Continental's hubs are Houston, Newark and Cleveland; Delta's hubs are Atlanta, Cincinnati, Dallas-Ft. Worth, New York-JFK, and Salt Lake City; Northwest's hubs are Detroit, Minneapolis and Memphis. Three of these hub designations deserve note. American's St. Louis hub did not start operating until 2001, after the acquistion of TWA, and it was reduced in size in 2003; Delta's DFW hub was closed in 2004; and Delta's JFK hub was not officially identified by the airline until 2005. Since switching a route's identify between PP and HS within the period under study creates complications, the fact that each of these airports did not have official hub status throughout the period is ignored, leading to some potential misclassification of routes. However, this problem is very minor for St. Louis, and the treatment of JFK as a Delta hub prior to 2005 may be appropriate in any case. ${ }^{13}$

The routes of Business Express, which provided service for both Delta and Northwest, were allocated using hub identities. Service with an endpoint at the Delta hubs in Atlanta, Salt Lake City, Dallas-Fort Worth, Cincinnati, and New York-JFK was assigned to Delta, while service with an endpoint at the Northwest hubs in Detroit, Minneapolis, and Memphis was assigned to Northwest. In addition, since Delta has significant operations at New York-LaGuardia and Boston, Business Express flights in and out of these airports were assigned to Delta as well.

Demographic data for route endpoints is drawn from the Census. The conventions used to assign census data to individual airports are described in the appendix. 


\section{Empirical Findings}

\section{4a. Basic patterns of new service}

To begin appraising the impact of RJs on airline service patterns, the first step is to consider all the new domestic service, regardless of aircraft type, that was introduced after 1996. ${ }^{14}$ The role of RJs can then be seen in proper context. In portraying the patterns of new service, the data from the four different airlines were pooled, so that the identities of particular carriers are suppressed. This approach is followed because the task of digesting four different service patterns for the individual carriers would be demanding and not very illuminating. In addition, service on a route was counted only if it involves at least 20 flights per month in each direction.

New service patterns for HS routes and PP routes are considered separately, and the results are shown in Table 2. The results pertain to routes that lacked any kind of service in 1996, and where new service of some type was introduced over the period 1997-2005. Service patterns seen on fewer than 10 routes are not reported. To interpret the service-type entries in the table, the "Jet, RJ" row in the HS panel pertains to HS routes where both mainline jet and RJ service were started (possibly at different times) during the 1997-2005 period and maintained during the period, and where no new turboprop service was started. Similarly, the "Jet" row pertains to HS routes where (mainline) jet service was started and maintained and no other type of service was introduced. The "RJ Intermittent" row pertains to HS routes where RJ service was started and stopped (and possibly restarted) during the period, and where no other type of service was present. The other entries have analogous interpretations. A handful of the PP routes are duplicates, served by different carriers.

Turning to the numerical information, the HS panel of the table shows that new service was started on 704 HS routes over the 1997-2005 period. On 244 of these routes, RJ service was started and maintained, with no other type of service provided. In the next most frequent case, intermittent jet service was started on 62 routes, while continuing jet service was started on 53 routes. Intermittent RJ service was started on 61 routes, while a mixture of intermittent jet and continuing RJ service was started on 46 routes. Mixed continuing jet and RJ service was started on 31 routes, and mixed continuing RJ and turboprop service was started on 24 
routes. The striking feature of these numbers is the dominance of the RJ service pattern, where new service by RJs is started and maintained, with no other type of service present. Thus, RJs played a key role over the period in expanding the linkages between hub airports and endpoint cities across the country.

The PP panel shows that new PP service was started on 434 routes over the period. As in the HS case, the most common new service type is RJ service that is started and maintained, with no other service type present. Such service is observed on 91 routes. Intermittent jet service, started on 89 routes, is the next most common case, with intermittent turboprop service, started on 72 routes, close behind. In addition, 44 PP routes gained continuing jet service, with no other service type present. The message of the PP panel is thus similar to that of the HS results, although not as dramatic: an important source of new PP service is RJ service that is started and maintained, with no other type of service present.

The bottom of Table 2 shows the breakdowns of the new HS and PP routes across the four airlines. One notable feature of these breakdowns is Continental's relatively small share in the total, especially in the PP case.

\section{4b. Service breakdowns by distance, population and income}

The theoretical analysis in section 2 suggested that RJ's may allow PP service in markets where such service was not economical previously. To begin the task of appraising this newroutes hypothesis, it is useful to compare the distributions of new RJ and jet service according to market characteristics. Three characteristics of interest are: $(i)$ the distance between the endpoints; (ii) market size, as measured by average of the endpoint populations; and (iii) market income, as measured by the average of the endpoint shares of high-income households (those with incomes above $\$ 75,000$ ). Although PP service is a principal focus, the service breakdowns across these categories are shown for both HS and PP routes.

In comparing the distributions of new jet and RJ service, subsets of the cases shown in Table 2 are considered. For jet service, only routes with continuing or intermittent jet service and no other service type are considered, and for RJ service, only routes with continuing or intermittent RJ service and no other service type are considered. The bottom panel of Table 3 shows the breakdowns by carrier for the resulting routes, revealing once again Continental's 
small share.

The upper panel of Table 3 shows the service breakdowns over four distance categories: less than 400 miles, 400 to 800 miles, 800 to 1200 miles, and more than 1200 miles. For both the HS and PP cases, the table shows that jet service is skewed toward the long distance categories, while RJ service is skewed toward the short distance categories. This finding, which is also reflected in the mean distances shown in the table, is not surprising given that RJs have a shorter range than mainline jets. However, a contributing factor may be the RJ's slight comfort disadvantage relative to mainline jets, which may help to limit RJ use on especially long routes.

Table 4 shows the service breakdowns over four market size categories: average endpoint population less than 1 million, between 1 and 2 million, between 2 and 6 million, greater than 6 million. The HS table shows noteworthy differences in the cell percentages in the largest and smallest population categories, with jet service dominating in the largest markets and RJ service dominating in smallest markets. The cell percentages in two middle categories are closer together but reflect the same skewness pattern. Thus, the new HS routes with the largest endpoints tend to attract jet service, while routes with smaller endpoints tend to attract RJ service. This pattern is also reflected in the mean average populations shown in the table.

By contrast, the pattern seen in the PP panel of Table 4 is less clear. In the three cells with the largest populations, jet service is slightly relatively skewed toward routes with large endpoints, but the smallest population cell contradicts this pattern. Indeed, the mean average populations are similar for the two types of service. This pattern is surprising given that one would expect endpoint populations on PP routes to play a bigger role in determining aircraft size than the populations on HS routes, given that the hub city is not a destination for connecting passengers.

Table 5 shows the service breakdowns over four income categories: an average endpoint share of high-income households less than 23\%, a share between $23 \%$ and $30 \%$, a share between $30 \%$ and $36 \%$, a share above $36 \%$. In the HS case, RJ service is slightly relatively skewed toward low-income markets, while in the PP case, no clear pattern is apparent (both outcomes are reflected in the mean values). Observe, however, that while few high-income routes have new 
HS service, such routes are well represented in the PP case.

Summing up, Tables 3-5 show that the markets gaining new jet point-to-point service were demographically similar to markets gaining new point-to-point service by RJs. The markets differed only in route distance, with RJ service skewed toward shorter routes. This conclusion appears to contradict the predictions of the theoretical analysis, which suggested that relatively thin city-pair markets will be the ones to attract new RJ point-to-point service, with jets serving larger markets. Since the data show that new jet and RJ service is occurring in similar markets, the evidence thus appears not to support this new-routes hypothesis. In other words, RJs appear not to have generated new PP service in markets where it was previously uneconomical.

\section{4c. Probit analysis}

Despite this tentative conclusion, this section of the paper further explores the question of whether RJs are serving new kinds of markets by adopting a methodology that goes beyond the simple comparisons in Tables 3-5. The first step is to identify those markets where PP jet service was provided in the pre-RJ era, prior to 1997. To find the market characteristics that led to such service, a probit equation is estimated on the universe of all possible PP routes, with the dependent variable equal to one for those routes where jet service was observed and zero for routes lacking PP jet service. The explanatory variables include the distance, population and income measures from above, along with other variables.

Next, the estimated equation is used to make out-of-sample predictions. In particular, the results are used to compute the mean predicted probability of PP jet service for routes that gained new service following the introduction of RJs. The key step, however, is to carry out this computation separately for routes that actually gained jet service and routes that actually gained RJ service. If RJs are indeed serving PP markets that could not be served economically by jets, then the probability of jet PP service in the markets that actually gained RJ service should be low.

The size of this probability is judged by comparing it to the predicted probability of jet PP service for markets that did in fact gain jet service in the RJ era. If RJs are indeed serving new kinds of PP markets, then the predicted probability of jet service should be lower for markets 
that gained RJ service than for markets that gained jet service.

To carry out this exercise, routes with PP jet service in 1994, 1995 or 1996 by any of the four airlines were identified. Then, routes shorter than 175 miles were dropped on the grounds that they may represent tag-end service or other anomalies, as were routes connecting endpoints with an average population of less than $75,000 .{ }^{15}$ The resulting set of routes was then collapsed to eliminate a handful of duplicate routes served by multiple airlines. The result was a set of $157 \mathrm{PP}$ routes served with jets by at least one of the four airlines in the 1994-1996 period.

The universe of possible routes was generated from a set of 305 airports in the contintental US, excluding the smallest endpoints. Potential PP routes were all possible airport combinations from this set with distances of at least 175 miles, a total of 42,001 routes. PP jet service was observed on only 157 of these routes, and the probit equation is intended to identify market characteristics that made such service likely.

The distance, population and income measures from above (denoted DIST, POP and INC75), appear in the probit equation along with several additional explanatory variables. ${ }^{16}$ The first is the dummy variable LEISURE, which indicates whether either endpoint of the route is Las Vegas or Orlando, both popular leisure destinations. The second variable (HUB) indicates whether either of the endpoints is a hub for any of the four airlines. Since PP routes in the sample by construction cannot include a hub endpoint for the carrier providing the service, routes with such endpoints are less likely to appear among those with PP service. Note, however, that an airline could provide PP service to the hub of a different carrier. The final explanatory variable (SERVBOTH) is a count of the number of carriers from among the four that served both endpoints of the route. Clearly, a requirement for PP service is the presence of at least one of the carriers at both endpoints. Interestingly, this condition is satisfied for $54 \%$ of the 42,001 potential PP routes. ${ }^{17}$

The probit results are shown in Table 6, with and without the SERVBOTH variable. The covariate means in the third column show that $18 \%$ of the observations with PP service have a hub endpoint (capturing PP service to some other carrier's hub), that $24 \%$ have either Las Vegas or Orlando as an endpoint, and that the average number of carriers serving both 
endpoints is 3.6 (close to the maximum possible value of 4 ). ${ }^{18}$

The coefficient estimates in the second column, where SERVBOTH is omitted, mostly conform to expectations, with all coefficients significant. PP jet service in a market is more likely when the average of the endpoint populations is high, when the average share of highincome households is high, and when one endpoint is Las Vegas or Orlando. PP service is less likely when an endpoint is a hub for one of the carriers. The distance variable is entered in quadratic fashion, and although the coefficient of the squared term (DIST2) is positive, the distance effect is negative over the relevant range given the dominance of the negative linear coefficient. Therefore, PP jet service is less likely on long routes, where the incentive to send passengers through a hub is evidently greater.

When SERVBOTH is added as an explanatory variable, its coefficient is positive and significant, as expected. However, INC75's coefficient becomes negative and insignificant in the presence of SERVBOTH. Apparently, the positive association between these variables (indicating that both endpoints of high-income routes tend to attract same-carrier service) precludes a separate measurement of INC75's effect.

Knowing that the explanatory variables perform well in explaining PP jet service in the pre-RJ era, attention can turn to the predicted probabilities discussed above, which are shown in the last few rows of Table 6. The within-sample predicted probabilities are shown first, and they indicate that the average predicted probability for the PP observations is 0.108 for the equation with SERVBOTH and 0.038 for the equation without this variable. While these probabilities are not large, they are much greater than the average predicted probabilities for observations without PP service, which equal 0.003 in both equations.

The out-of-sample predicted probabilities are shown in the next two rows. They are computed using the PP jet and RJ routes shown in Tables 3-5, which have continuing or intermittent service and no other type of service. Routes shorter than 175 miles are dropped, which (slightly) reduces the number of jet routes to 128 and the number of RJ routes to 121.

The predicted probability of PP jet service on the routes that gained such service after 1996 is 0.095 in the first equation and 0.036 in the second, values that are very close to the in-sample probabilities. The last row of the table shows the predicted probability of PP jet service on 
the routes that gained RJ service after 1996, equal to 0.105 and 0.044 . These values are very similar to the probabilities in the previous row and to the in-sample predicted probabilities.

This similarity reinforces the tentative conclusion reached above, namely, that the introduction of RJs did not appear to extend PP service to new types of markets, as predicted under the new-routes hypothesis. In particular, the routes gaining PP service by RJs after 1996 were not routes unlikely to have gained jet PP service had the RJ never been introduced. Instead, their probability of gaining jet service was nearly the same as the probability for routes that did gain jet service after 1996. Moreover, the routes that gained RJ service had about the same probability of PP jet service as the routes that already enjoyed it prior to 1997.

This conclusion partly reflects the fact that the demographic characteristics of PP routes gaining jet and RJ service are very similar. While this fact was seen in the population and income comparisons in Tables 4 and 5, the deletion of routes shorter than 175 miles slightly alters the relevant numbers. The resulting means of POP and INC75 for the routes gaining jet service are 4.2 million and $26 \%$, respectively, while the means of these variables for the routes gaining RJ service are 4.1 million and 28\%, values that closely match. Moreover, this similarity extends as well to the demographics of the routes having pre-1997 jet PP service, which have mean POP and INC75 values of 3.6 million and 26\%, as seen in Table 6. These values are close to the previous numbers, but they show that new PP service involves markets that are slightly larger and richer than markets enjoying PP jet service prior to 1997.

One significant disparity, noted above, is in the distance measures for the different routes. Table 6 shows that the average distance of the pre-1997 PP jet routes is 800 miles, while the average distances for the new jet and RJ PP routes are 1205 and 590 miles, respectively. ${ }^{19}$ While these distance differences are substantial, they are not sufficient (when combined with variation in the other explanatory variables) to generate large differences in the predicted probabilities across the three types of routes. But their existence yields a simple conclusion about how the emergence of RJs has affected PP service. In particular, while PP service following the introduction of RJs focused on markets with demographics broadly similar to those of markets with pre-1997 PP jet service, long-distance markets within this group were served by jets and short-distance markets by RJs. Thus, it appears that the introduction of 
RJs has mainly allowed a better tailoring of aircraft to market distance in PP service.

\subsection{Patterns of replacement and supplementation}

While the preceding analysis has focused on new service, RJs have been widely used to replace and supplement existing service. The relevant replacement patterns are shown in Table 7. Of the 152 HS routes where jet service was discontinued after 1996, RJs replaced this service on 109 routes. Of the 184 HS routes where turboprop service was discontinued after 1996, RJs replaced this service on 105 routes. Replacement of jets by turboprops or turboprops by jets was rare, and in addition, many routes where jet service was discontinued saw no replacements at all. By contrast, on PP routes where jet or turboprop service was discontinued, replacement was rare, and if it occurred at all, RJs provided the service. Evidently, discontinuation of service on a PP route signaled an unsuccessful market where replacement was not desirable.

Table 7 also shows the changes in flight frequencies for those routes where replacement involved RJs. As can be seen, on HS routes where RJs replaced jets, frequency rose, and on all routes where RJs replaced turboprops, frequency fell. ${ }^{20}$ These changes are in line with the change in aircraft size, in the sense that downsizing a route's aircraft should allow higher frequencies, while upsizing (as usually occurs when RJs replace turboprops) should reduce frequencies. Thus, Table 7 clearly shows the frequency advantage of RJs over jets, as discussed in the introduction. Note that while frequency dropped on the single PP route where RJs replaced jets, this outcome appears to be an anomaly.

Like replacement, supplementation of jet service on PP routes was rare. Service supplementation was common, however, on HS routes, as shown in Table 8. Of 603 HS routes with jet service in 1996 that was not discontinued, RJs supplemented this service on 261 routes and

turboprops supplemented on 16 routes, leaving 326 routes without supplementation. ${ }^{21}$ On routes where RJ supplementation occurred, frequency rose by $17.5 \%$.

The figures in Tables 7 and 8 show that, while providing service on many routes not previously served, RJs played two further important roles by replacing and supplementing existing service on a large number of additional routes. When these outcomes occurred on previous jet routes, flight frequencies rose, enhancing the service quality provided to passengers. 


\section{Conclusion}

This paper has explored the impact of the regional jet, an important new technological innovation in the airline industry, on service patterns and service quality. The evidence shows that RJs were used to provide service on a large number of new hub-and-spoke and point-to-

point routes. In addition, they replaced discontinued jet and turboprop service on many HS routes, as well as supplementing continuing jet service on such routes. When replacement or supplementation by RJs occurred, passengers benefited from better service quality via higher flight frequencies.

The paper's theoretical analysis predicted that the frequency advantage of RJs over jets, a consequence of their small size, should have led to the emergence of point-to-point service in thin markets where such service was previously uneconomical. In these markets, use of large aircraft would have required flight frequencies so low as to make service nonviable, while the RJ's smaller size would support viable frequencies. However, the evidence contradicts this "new-routes" hypothesis, showing that markets attracting new point-to-point service by RJs had demographic characteristics similar to those of markets that already had jet pointto-point service or attracted it after 1996. Therefore, the innovation associated with RJs did not appear to lead to the emergence of new airline "products" (new route types). Instead, the RJ helped the airlines to improve the quality of their existing products through more attractive flight frequencies, while allowing operational gains through a better tailoring of aircraft characteristics to route distances.

Given the plausibility of the new-routes hypothesis, the failure to find empirical support for it is somewhat puzzling. One possible explanation for the lack of support relates to an important institutional constraint that governs airline operations, known as the "scope clause." These union-contract provisions limit RJ operations by the regional subsidiaries of major carriers, reflecting union fears that RJ growth will reduce employment levels for mainline jet pilots. With RJ usage limited by scope clauses, the major carriers may have been unable deploy RJs in their full range of potential uses. New point-to-point service may have been one of the uses blocked by these constraints, explaining its absence in the data. ${ }^{22}$

While this view suggests that independent regional operators, which are not affected by 
scope clauses, may be have been freer than the major airlines to initiate new point-to-point RJ service, data on their operations are unavaiable for much of the sample period, as explained above. However, the recently announced plans of ExpressJet, a regional carrier released by Delta from a portion of its feeder duties, provide some anecdotal confirmation of the newroutes hypothesis. ExpressJet intends to use its surplus RJs to offer point-to-point service in a number of relatively thin city-pair markets, with San Diego-Omaha being one example. Given this evidence, the new-routes hypothesis may be more relevant than the present results indicate. 


\section{Appendix}

Airports were assigned to a metropolitan statistical area (MSA) based on the name of the airport. Most airports identify themselves as serving a specific city, and therefore a matching MSA, making the assignment of census data unambiguous. However, ambiguity arises in two special cases: $(i)$ where one airport serves multiple MSAs, and $(i i)$ where multiple airports serve a given MSA.

In case $(i)$, the population-weighted average of INC75 for the relevant MSAs was computed. Affected airports were CAK, where the Akron, $\mathrm{OH}$ and Canton-Massillon, $\mathrm{OH}$ MSAs were combined; ELM, where the Corning, NY and Elmira, NY MSAs were combined; MAF, where the Midland, TX and Odessa, TX MSAs were combined; RDU, where the Raleigh and Durham, NC MSAs were combined. For the Hartford-Springfield International Airport, BDL, the airport was assigned to the Hartford, CT, MSA due to the longer distance to Springfield, MA.

In case $(i i)$, the same MSA was assigned to each airport in the area, unless it was possible to assign a Metropolitan Division to the airport. For the Los Angeles MSA, LAX was assigned to the Los Angeles Metropolitan Division and Orange County (SNA) to the Santa Ana-Anaheim-Irvine Division. For the San Francisco Bay Area, San Francisco (SFO) was assigned to the San Francisco-San Mateo-Redwood City Division, and Oakland (OAK) to the Oakland-Fremont-Hayward Division. San Jose (SJC) was assigned to the San Jose-SunnyvaleSanta Clara, CA MSA. In the Chicago area, O'Hare (ORD) and Midway (MDW) were assigned to the Chicago MSA. For the New York City area, LaGuardia (LGA), John F. Kennedy (JFK), and Newark (EWR) were assigned to the New York-North New Jersey-Long Island MSA. Islip (ISP) and White Plains (HPN) were assigned to the Nassau-Suffolk and New York-White Plains Metropolitan Divisions respectively.

Several airports do not fall into a MSA or could not be easily assigned to a Metropolitan

Division in a large MSA, and for these cases, census data were gathered for the city in which airport is located. These airports are Traverse City, MI, Pasco, WA, Montrose, CO, Missoula, MT, Melbourne, FL, Jackson, WY, Helena, MT, Gunnison, CO, Bozeman, MT, Vail, CO, Kailspell, MT, Meridian, MS, Butte, MT, Hanover, NH Minot, ND, Harlingen, TX, Temple, 
TX, Cody, WY, Burbank, CA, Long Beach, CA, Palm Springs, CA, Aspen, CO, Durango, CO, Hayden, CO, Key West, FL, Marathon, FL, Brunswick, GA, Burlington, IA, Presque Isle, ME, Nantucket, MA. Due to the lack of available data, Martha's Vineyard and Hyannis, MA were assigned to their respective counties of Barnstable and Dukes. 


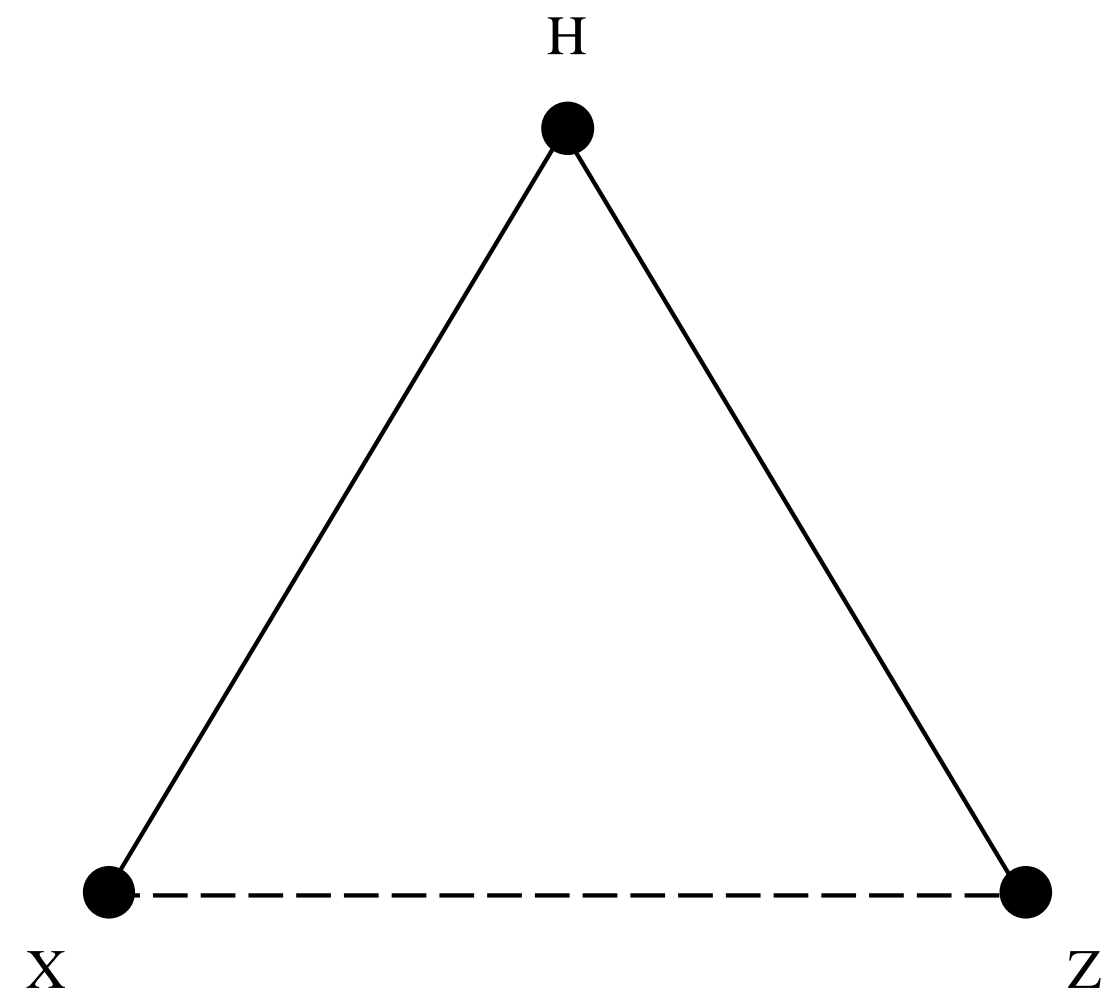

Figure 1: Route Structure 
Table 1

\section{RJ Routes}

\begin{tabular}{lr}
\hline \hline Year & Number of Routes \\
\hline 1990 & 6 \\
1991 & 14 \\
1992 & 55 \\
1993 & 86 \\
1994 & 99 \\
1995 & 97 \\
1996 & 74 \\
1997 & 100 \\
1998 & 158 \\
1999 & 263 \\
2000 & 460 \\
2001 & 564 \\
2002 & 707 \\
2003 & 854 \\
2004 & 925 \\
2005 & 1091 \\
\hline \hline
\end{tabular}


Table 2

\section{Patterns of New Service}

HS routes

\begin{tabular}{lrrlrr}
\hline \hline Service type & routes & share & Service type & routes & share \\
\hline Jet & 53 & .08 & Jet & 44 & .10 \\
RJ & 244 & .35 & RJ & 91 & .21 \\
Turbo & 38 & .05 & Turbo & 14 & .03 \\
Jet intermittent & 62 & .09 & Jet intermittent & 89 & .21 \\
RJ intermittent & 61 & .09 & RJ intermittent & 35 & .08 \\
Turbo intermittent & 29 & .04 & Turbo intermittent & 72 & .17 \\
Jet, RJ & 31 & .04 & Jet intermittent, RJ & 10 & .02 \\
RJ, Turbo & 24 & .03 & RJ, Turbo both intermittent & 20 & .05 \\
Jet, RJ both intermittent & 20 & .03 & & & \\
RJ, Turbo intermittent & 17 & .02 & & &
\end{tabular}

\begin{tabular}{lrrlrr}
\hline \hline Carrier & routes & share & Carrier & routes & share \\
\hline American & 181 & .26 & American & 157 & .36 \\
Continental & 108 & .15 & Continental & 21 & .05 \\
Delta & 218 & .31 & Delta & 140 & .32 \\
Northwest & 197 & .28 & Northwest & 116 & .27 \\
\hline Total & 704 & Total & \multicolumn{2}{|c}{434} & \\
\hline \hline
\end{tabular}


Table 3

Distribution of New Jet and RJ Service by Distance

HS routes

PP routes

\begin{tabular}{|c|c|c|c|c|c|}
\hline \multirow{2}{*}{$\begin{array}{l}\begin{array}{l}\text { Distance } \\
\text { in miles }\end{array} \\
<400\end{array}$} & \multicolumn{2}{|c|}{$\begin{array}{c}\text { Jet Routes RJ Routes } \\
\text { (Column share) }\end{array}$} & \multirow{2}{*}{$\begin{array}{l}\begin{array}{l}\text { Distance } \\
\text { in miles }\end{array} \\
<400\end{array}$} & \multicolumn{2}{|c|}{$\begin{array}{c}\text { Jet Routes RJ Routes } \\
\text { (Column share) }\end{array}$} \\
\hline & 5 & 31 & & 20 & 34 \\
\hline & $(.04)$ & $(.10)$ & & $(.15)$ & $(.27)$ \\
\hline \multirow[t]{2}{*}{400 to 800} & 8 & 183 & 400 to 800 & 10 & 68 \\
\hline & $(.07)$ & $(.60)$ & & $(.08)$ & $(.54)$ \\
\hline \multirow[t]{2}{*}{800 to 1200} & 26 & 82 & 800 to 1200 & 60 & 21 \\
\hline & $(.23)$ & $(.27)$ & & $(.45)$ & $(.17)$ \\
\hline \multirow[t]{2}{*}{$\geq 1200$} & 76 & 9 & $\geq 1200$ & 43 & 3 \\
\hline & $(.66)$ & $(.03)$ & & $(.32)$ & $(.02)$ \\
\hline \multirow{2}{*}{$\begin{array}{l}\text { total routes } \\
\text { mean distance }\end{array}$} & 115 & 305 & total routes & 133 & 126 \\
\hline & 1461 & 682 & mean distance & 1165 & 571 \\
\hline Carrier & Jet Routes & RJ Routes & Carrier & Jet Routes & RJ Routes \\
\hline American & 40 & 78 & American & 52 & 41 \\
\hline Continental & 22 & 56 & Continental & 9 & 11 \\
\hline Delta & 33 & 116 & Delta & 44 & 56 \\
\hline Northwest & 20 & 55 & Northwest & 28 & 18 \\
\hline
\end{tabular}


Table 4

Distribution of New Jet and RJ Service by Population

HS routes

$\mathrm{PP}$ routes

\begin{tabular}{lccccc}
\hline \hline $\begin{array}{l}\text { Average of } \\
\text { Endpoint Pops. }\end{array}$ & $\begin{array}{r}\text { Jet Routes } \\
(\text { Column } \text { share })\end{array}$ & $\begin{array}{c}\text { Average of } \\
\text { Endpoint Pops. }\end{array}$ & $\begin{array}{r}\text { Jet Routes } \\
\text { (Column share })\end{array}$ \\
\hline$<1$ million & 4 & 31 & $<1$ million & 16 & 8 \\
& $(.03)$ & $(.10)$ & & $(.12)$ & $(.06)$ \\
1 to 2 million & 27 & 84 & 1 to 2 million & 38 & 42 \\
& $(.23)$ & $(.28)$ & & $(.29)$ & $(.33)$ \\
2 to 6 million & 62 & 155 & 2 to 6 million & 35 & 42 \\
& $(.54)$ & $(.51)$ & & $(.26)$ & $(.33)$ \\
$\geq 6$ million & 22 & 35 & $\geq 6$ million & 44 & 35 \\
& $(.19)$ & $(.11)$ & & $(.33)$ & $(.28)$ \\
\hline total routes & 115 & 305 & total routes & 133 & 126 \\
mean avg. pop. & $3.9 \mathrm{~m}$. & $3.2 \mathrm{~m}$. & mean avg. pop. & $4.1 \mathrm{~m}$. & $4.0 \mathrm{~m}$. \\
\hline \hline
\end{tabular}


Table 5

Distribution of New Jet and RJ Service by Income

HS routes

\begin{tabular}{|c|c|c|c|c|c|}
\hline \multirow{2}{*}{$\begin{array}{l}\text { Average of High } \\
\text { Income Shares } \\
<23 \%\end{array}$} & \multicolumn{2}{|c|}{$\begin{array}{c}\text { Jet Routes RJ Routes } \\
\text { (Column share) }\end{array}$} & \multicolumn{3}{|c|}{$\begin{array}{lr}\text { Average of High } & \text { Jet Routes RJ Routes } \\
\text { Income Shares } & \text { (Column share) }\end{array}$} \\
\hline & 22 & 67 & $<23 \%$ & 34 & 35 \\
\hline & $(.19)$ & $(.22)$ & & $(.26)$ & $(.28)$ \\
\hline \multirow[t]{2}{*}{$23 \%$ to $30 \%$} & 51 & 191 & $23 \%$ to $30 \%$ & 45 & 29 \\
\hline & $(.44)$ & $(.63)$ & & $(.34)$ & $(.23)$ \\
\hline \multirow[t]{2}{*}{$30 \%$ to $36 \%$} & 41 & 46 & $30 \%$ to $36 \%$ & 42 & 41 \\
\hline & $(.36)$ & $(.15)$ & & $(.32)$ & $(.33)$ \\
\hline \multirow[t]{2}{*}{$\geq 36 \%$} & 1 & 1 & $\geq 36 \%$ & 12 & 21 \\
\hline & $(.01)$ & $(.00)$ & & $(.09)$ & $(.17)$ \\
\hline total routes & 115 & 305 & total routes & 133 & 126 \\
\hline mean average share & $28 \%$ & $27 \%$ & mean average share & $28 \%$ & $28 \%$ \\
\hline
\end{tabular}


Table 6

\section{Probit Results ${ }^{\dagger}$}

\begin{tabular}{|c|c|c|c|}
\hline Covariate & & efficients & $\begin{array}{c}\text { Covariate mean for } \\
\text { obs. with service }\end{array}$ \\
\hline CONSTANT & $\begin{array}{l}-3.436^{*} \\
(0.208)\end{array}$ & $\begin{array}{l}-2.540^{*} \\
(0.139)\end{array}$ & - \\
\hline DIST & $\begin{array}{l}-0.155^{*} \\
(0.014)\end{array}$ & $\begin{array}{l}-0.114^{*} \\
(0.011)\end{array}$ & 800 \\
\hline DIST2 & $\begin{array}{c}0.004^{*} \\
(0.000)\end{array}$ & $\begin{array}{c}0.002^{*} \\
(0.000)\end{array}$ & - \\
\hline POP & $\begin{array}{c}0.131^{*} \\
(0.016)\end{array}$ & $\begin{array}{c}0.157^{*} \\
(0.013)\end{array}$ & $3,576,022$ \\
\hline INC75 & $\begin{array}{l}-0.004 \\
(0.008)\end{array}$ & $\begin{array}{c}0.012^{*} \\
(0.006)\end{array}$ & 25.8 \\
\hline LEISURE & $\begin{array}{c}1.080^{*} \\
(0.108)\end{array}$ & $\begin{array}{c}1.200^{*} \\
(0.090)\end{array}$ & 0.24 \\
\hline HUB & $\begin{array}{l}-0.652^{*} \\
(0.104)\end{array}$ & $\begin{array}{l}-0.344^{*} \\
(0.095)\end{array}$ & 0.18 \\
\hline SERVBOTH & $\begin{array}{c}0.625^{*} \\
(0.044)\end{array}$ & - & 3.60 \\
\hline Routes & Predicted 1 & babilities & \\
\hline Jet PP 1994-96 & 0.108 & 0.038 & \\
\hline Jet PP Post-1996 & 0.095 & 0.036 & \\
\hline RJ PP Post-1996 & 0.105 & 0.044 & \\
\hline
\end{tabular}

${ }^{\dagger}$ Dependent variable equals 1 for routes with 1994-1996 jet PP service and 0 otherwise; asterisks indicate coefficients significant at the $5 \%$ level; observations $=42,001$. 
Table 7

\section{Replacement Patterns}

HS routes $\quad$ PP routes

\begin{tabular}{lrlr}
\hline \hline $\begin{array}{l}\text { Outcome } \\
\text { Discontinued (152) }\end{array}$ & Routes where Jet & Outcome & $\begin{array}{c}\text { Routes where Jet } \\
\text { Discontinued (102) }\end{array}$ \\
RJ replaces & 109 & RJ replaces & 1 \\
Turbo replaces & 6 & Turbo replaces & 0 \\
No replacement & 37 & No replacement & 101 \\
& & & \\
\hline
\end{tabular}

Avg. frequency change $+66.4 \%$ with RJ replacement

Avg. frequency change $-34.9 \%$ with RJ replacement

HS routes

$\mathrm{PP}$ routes

\begin{tabular}{lrlr}
\hline \hline $\begin{array}{l}\text { Outcome } \\
\text { Doutes where Turbo } \\
\text { Discontinued }(184)\end{array}$ & Outcome & $\begin{array}{r}\text { Routes where Turbo } \\
\text { Discontinued (57) }\end{array}$ \\
\hline $\begin{array}{l}\text { RJ replaces } \\
\text { Jet replaces }\end{array}$ & 105 & RJ replaces & 5 \\
No replacement & 8 & Jet replaces & 0 \\
& 71 & No replacement & 52 \\
Avg. frequency change & $-33.9 \%$ & Avg. frequency change & $-32.9 \%$ \\
with RJ replacement & & with RJ replacement & \\
\hline \hline
\end{tabular}


Table 8

HS Supplementation Patterns

\begin{tabular}{lr}
\hline \hline Outcome & Jet HS Routes $(603)$ \\
\hline RJ supplements & 261 \\
Turbo supplements & 16 \\
No supplementation & 326 \\
\hline & \\
Avg. frequency change & $+17.5 \%$ \\
with RJ supplementation & \\
\hline \hline
\end{tabular}




\section{References}

Babikian, R., Lukacho, S.P., Waitz, I.A., 2002. The historical fuel efficiency characteristics of regional aircraft from technological, operational, and cost perspectives. Journal of Air Transport Management 8, 389-400.

Brueckner, J.K, 2004. Network structure and airline scheduling. Journal of Industrial Economics 52, 291-311.

Dresner, M., Windle, R., Zhou, M., 2002. Regional jet services: supply and demand. Journal of Air Transport Management 8, 267-273

Forbes, S.J., Lederman, M., 2005. Control rights, network structure and vertical integration: Evidence from regional airlines. Unpublished paper, University of California, San Diego.

General Accouting Office, 2001. Aviation Competition: Regional Jet Services Yet to Reach Many Small Communities. GAO-01-344, US General Accounting Office, Washington D.C. 


\section{Footnotes}

*We thank Volodymyr Bilotkach, Ricardo Flores-Fillol, Darin Lee and Ken Small for comments. Any shortcomings in the paper, however, are our responsibility.

${ }^{1}$ See Babikian et al. (2002).

${ }^{2}$ Again, see Babikian et al. (2002).

${ }^{3}$ Despite increased RJ usage, reports in the trade press document recent growth in the demand for ATR and Bombardier turboprops. This development reflects both the general traffic rebound in the airline industry and the fact that turboprops are more economical than RJs on shorter routes.

${ }^{4}$ The details of this derivation are as follows. In Brueckner's model, consumers must commit to travel before knowing their preferred departure times, which are uniformly distributed around a circle. Letting $T$ denote the time circumference of the circle, consumer utility then depends on expected schedule delay, which equals $T / 4 f$, where $f$ is number of (evenly spaced) flights operated by the airline. This expression gives the expected difference between the consumer's preferred departure time and the nearest flight time. Letting $\nu$ be a disutility parameter, the cost of schedule delay is then $\nu T / 4 f \equiv \gamma / f$, where $\gamma=\nu T / 4$. Utility for a consumer is given by $c+b-\gamma / f$, where $b$ is travel benefit and $c$ is consumption expenditure. Since consumption expenditure equals income $w$ minus the airfare $p$, utility can then be written $w-p+b-\gamma / f$. Letting $u$ denote the utility from the consumer's outside option, which might represent a different travel mode or not traveling at all, surplus extraction by the airline implies that $w-p+b-\gamma / f=u$, or $p=y-\gamma / f$, where $y \equiv w+b-u$.

${ }^{5}$ If the direct route were longer than the individual connecting routes (if the triangle in Figure 1 were flattened), this cost disadvantage would be amplified. This cost specification can be derived from the approach of Brueckner (2004), as follows. Brueckner assumes that cost per flight entails a fixed cost $\mu$ and a variable cost per seat $\eta$, so that cost per flight equals $\mu+\eta s$ and cost per seat is $\mu / s+\eta$. With different aircraft sizes in direct and connecting service, costs per seat are then $\tau^{d}=\mu / s^{d}+\eta$ and $\tau^{c}=\mu / s^{c}+\eta<\tau^{d}$.

${ }^{6}$ Specifically, convexity is ensured when $\gamma_{A}>2 \widetilde{\gamma}$, where $\widetilde{\gamma}$ from above is the value $\gamma$ in the population. Since $\gamma_{A}>\gamma_{B}$ and $\widetilde{\gamma}$ is a weighted average of these variables, $\gamma_{A}>\widetilde{\gamma}$ holds. But the inequality $\gamma_{A}>2 \widetilde{\gamma}$ is more stringent, and rearrangement shows that it requires the inequalities $\delta<1 / 2$ and $\gamma_{A}>[2(1-\delta) /(1-2 \delta)] \gamma_{B}$ to both be satisfied. For example, if $\delta=1 / 3$, then the latter inequality reduces to $\gamma_{A}>4 \gamma_{B}$, indicating that the relatively scarce A-types (business travellers) must be four times as averse to schedule delay as the B-types, 
a plausible restriction.

${ }^{7}$ Divisions of traffic where some or all of the B-types travel direct along with the A-types are also possible, but the given division seems most natural and is thus the focus of the analysis.

${ }^{8}$ With a smaller $q^{c}$ leading to a lower connecting frequency, the revenue loss for local passengers rises with $\theta_{B}$, producing a negative impact on profit captured by the term involving $-2 \widetilde{\gamma}$. This decline in profit is offset by a smaller revenue loss for connecting XZ passengers when $\theta_{B}$ rises, but the net profit impact remains negative given $\gamma_{B}<2 \widetilde{\gamma}$.

${ }^{9}$ Recall from footnote 7 that $\gamma_{A}>2 \widetilde{\gamma}$ is assumed to hold.

${ }^{10}$ The assumption $\tau^{d}=\tau^{c}$ presumes that the three routes in Figure 1 are of equal length. The ensuing argument would be unaffected if $\tau^{d} \neq \tau^{c}$.

${ }^{11}$ Each of these expressions contains both positive and negative terms, and the negative terms must dominate for the given conditions to hold.

${ }^{12}$ The BTS defines large certificated air carriers as airlines that hold Certificates of Public Convenience and Necessity issued by the U.S. Department of Transportation (DOT) and operate aircraft with seating capacity of more than 60 seats or a maximum payload capacity of more than 18,000 pounds.

${ }^{13}$ In the case of STL, the only American service in the years 1996-1999 was from the hubs ORD and DFW (making the HS designation of STL routes correct for these years), while one PP route appeared in 2000 and four more in 2001, which are then misclassified as HS routes (a large number of STL HS routes emerge in 2002 after American's takeover of the TWA hub). Since this approach understates the count of PP routes, which are of special interest, it is conservative and thus defensible. In the case of JFK, the number of Delta routes with this endpoint was in the low twenties over the 1996-2003 period, increasing to 31 in 2004 and 36 in 2005. This information suggests that viewing JFK as a Delta hub over the entire sample period is appropriate, even though it does not gain this status officially until 2005.

${ }^{14}$ Because of their atypical nature, routes to Hawaii are not considered.

${ }^{15}$ Tag-end service occurs in remote parts of the country where hub-bound flights from a small city may make an intermediate stop at another small airport to collect passengers, giving a false impression of PP service. Routes where the average of the endpoint populations was less than 75,000 were also dropped. 
${ }^{16}$ In the probit estimation, DIST is measured in hundreds of miles and POP is measured in millions.

${ }^{17}$ An additional covariate measured the average white-collar employment share in the endpoint cities, but this variable performed poorly.

${ }^{18}$ The means of HUB, LEISURE and SERVBOTH for the routes gaining jet service are 0.17 , 0.26 and 3.77, respectively, while the means of these variables for the routes gaining RJ service are $0.19,0.13$, and 3.34 .

${ }^{19}$ Because of the elimination of PP routes shorter than 175 miles, these means are slightly larger than those in Table 2.

${ }^{20}$ The frequency change is computed from 1997 to 2005, and it is based on average frequency during the years with only jet service and average frequency during subsequent years when only RJ service was present.

${ }^{21}$ Supplementation by both RJs and turboprops occurred on 12 routes.

${ }^{22}$ We thank Darin Lee for this explanation. 